\title{
Copper Release Kinetics and Ageing of Insulation Paper in Oil-Immersed Transformers
}

\author{
Olena Sevastyanova1,2, Bogdan Pasalskiy3 ${ }^{3}$, Boris Zhmud ${ }^{4 *}$ \\ ${ }^{1}$ Departmentof Fibre and Polymer Technology, KTH-The Royal Institute of Technology, Stockholm, Sweden \\ ${ }^{2}$ Wallenberg Wood Science Centre, KTH-The Royal Institute of Technology, Stockholm, Sweden \\ ${ }^{3}$ Kyiv National University of Trade and Economics, Kyiv, Ukraine \\ ${ }^{4}$ Sveacon Consulting, Stockholm, Sweden \\ Email: ${ }^{\text {boris.zhmud@sveacon.se }}$
}

Received 27 July 2015; accepted 23 August 2015; published 26 August 2015

Copyright (C) 2015 by authors and Scientific Research Publishing Inc.

This work is licensed under the Creative Commons Attribution International License (CC BY).

http://creativecommons.org/licenses/by/4.0/

(c) (i) Open Access

\begin{abstract}
The paper provides a general overview of chemical processes leading to the degradation of oilpaper insulation in oil-immersed electrical current transformers. Previous knowledge available in literature is complemented by new results placing a specific emphasis on the physicochemical factors which affect the copper release in the insulation oil and the oil oxidation kinetics. It is demonstrated that various ageing processes interact with each other, with one or another process dominating under specific conditions. Comprehensive but disjoint studies focusing on separate sub-processes may produce rather misleading results, and occasionally, lie behind rather irrelevant quality demands imposed on the insulating liquids.
\end{abstract}

\section{Keywords}

Transformer Oil, Insulating Oil, Copper Corrosion, Paper Degradation, Ageing

\section{Introduction}

Excessive heat produced during high-load operation of oil-filled transformers leads to accelerated oxidation of oil and degradation of the cellulosic insulating material on copper windings. Increased acidity and humidity not only degrade the insulation capacity of the oil-paper system but also create a potentially corrosive environment within the transformer. This necessitates oil replacement or reconditioning at intervals. However, replacing the

"Corresponding author. 
oil does not restore the paper to its original state, while it is generally accepted that the primary cause of the majority of ageing-related transformer failures is the degradation of the insulating paper and not of the oil. Therefore, by focusing either on the oil stability or on the paper stability alone, one gets only a one-sided view of the problem. A growing awareness of this initiated step towards studying the ageing chemistry for the oil-paper insulation system as a whole [1]-[4]. These studies suggest conclusively that various ageing processes occurring in oil-immersed transformers interact with each other, as shown in Figure 1.

For instance, the humid and hot environment in countries with a tropic climate may reduce the efficiency of cooling and facilitate accumulation of water inside the transformer, both due to more intense humidity intake and due to increased solubility of water in oil at elevated temperatures. This is especially true for free breathing transformers. Water is also a natural product of oil oxidation. Water and oxygen trigger corrosion of metallic parts. The subsequent release of transitional metal ions, in particular copper, will catalyse further oxidation of the oil [5]. Oil oxidation products, some of which have acidic character, will gradually accumulate in oil, contributing to protonic conductivity and eventually causing unwanted electrochemical processes, e.g. anodic oxidation of antioxidants, water and carboxylic acids to peroxides, etc. [6]. Increased acidity also spurs the degradation of paper, mainly by catalysing depolymerization and dehydration reactions. Paper degradation products, including polycarboxylic acids and furanic structures, are good complexing agents for transitional metal ions. The complexation may in some cases shift the electrochemical potential for copper dissolution to a level that makes acidic attack possible. This shows that, the ageing process is self-accelerating with time in a sense that the products generated at early stages of the process trigger other unwanted reactions later on.

\section{The Chemistry of the Ageing Processes in Oil-Immersed Transformers}

\subsection{Oil Oxidation}

Traditionally, the major emphasis in studies of transformer's behaviour has been on the oil stability. It is commonly accepted that the oxidation proceeds via a free-radical mechanism involving the formation of peroxy radicals. Transition metal ions, notably copper, acting as initiators of the radical reactions, are known to increase the oxidation rate of hydrocarbons. The classical theory of the copper-catalysed oxidation process assumes the following initiation step,

$$
\begin{gathered}
\mathrm{Cu}^{2+}+\mathrm{RH} \rightarrow \mathrm{Cu}^{+}+\mathrm{H}^{+}+\mathrm{R}^{\bullet} \\
\mathrm{R}^{\bullet}+\mathrm{O}_{2} \rightarrow \mathrm{ROO}^{\bullet}
\end{gathered}
$$

followed by regeneration of $\mathrm{Cu}^{2+}$ ions by reaction with dissolved oxygen,

$$
4 \mathrm{Cu}^{+}+\mathrm{O}_{2}+4 \mathrm{H}^{+} \rightarrow 4 \mathrm{Cu}^{2+}+2 \mathrm{H}_{2} \mathrm{O}
$$

This mechanism- homogeneous catalytic oxidation-is supported by the fact that the concentration of peroxides in oils oxidized by air increases with increasing the copper concentration [5].

A concomitant increase in acidity promotes the release of new copper ions by leaching of thin oxide films invariably present at the surface of copper conductors. The typical thickness of such oxide films is 10 to $200 \mathrm{~nm}$ and it has a non-stoichiometric composition $\mathrm{Cu}_{x} \mathrm{O}(x>1)$. Apart from the two common copper oxides, $\mathrm{Cu}_{2} \mathrm{O}$ and $\mathrm{CuO}$, corresponding to one- and two-valent copper, respectively, more exotic metastable compounds, such as

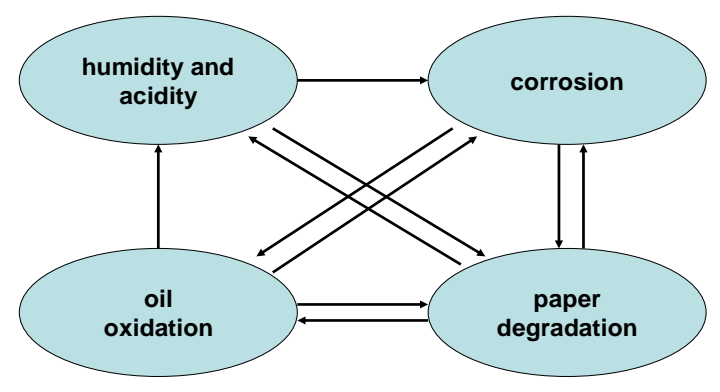

Figure 1. Interaction between different degradative processes occurring in oil-immersed transformers. 
$\mathrm{Cu}_{64} \mathrm{O}, \mathrm{Cu}_{8} \mathrm{O}$, and $\mathrm{Cu}_{4} \mathrm{O}$, were detected at initial oxidation stages [7]-[9]. It is doubtful, though, that the latter formulas describe individual chemical compounds-most likely, one deals with non-stoichiometric compounds formed by inclusion of oxygen into the crystal lattice of copper.

There are indications that $\mathrm{Cu}_{2} \mathrm{O}$ is more active in generation of radicals than $\mathrm{CuO}$ [10]. The two-valent copper ions, $\mathrm{Cu}(\mathrm{II})$, can be stabilized by complexation with a variety of bi- or poly-dentate ligands, such as aminoacids, hydroxycarboxylic acids, porphyrins, etc. The complexation will normally stabilize the two-valent state if the ligand has a free electron pair that can be accommodated by the vacant d-orbital of the $\mathrm{Cu}^{2+}$ ion (as is the case for amines, water, and carboxylic acids). However, in fresh insulating oils, especially in hydrotreated ones, there does not appear to be any such compounds, and therefore - at least in the beginning - the predominant state of dissolved copper is $\mathrm{Cu}(\mathrm{I})$. This conforms to the fact that the single-valent copper is stabilized by complexation with a variety of "soft" ligands whose electron orbitals are capable of hybridization with occupied d-orbitals of the $\mathrm{Cu}^{+}$ion; a number of such complexes with olefins, carbonyls, acetylenes as ligands have been described in the literature [11]. The presence of single-valent $\mathrm{Cu}(\mathrm{I})$ ions in oxidized insulating oil has also been directly confirmed by neocuproine titration [10].

In the excess of dissolved oxygen (40 to $50 \mathrm{ppm}$ in open-breathing transformers), the $\mathrm{Cu}(\mathrm{II}) / \mathrm{Cu}(\mathrm{I})$ equilibrium is shifted towards copper (I) ions being oxidized to copper (II) ions triggering the radical oxidation process. However, if only one specific oxidation state is stabilized by complexation, the catalytic effect of copper may diminish, either because the resulting $\mathrm{Cu}(\mathrm{II})$ complex cannot abstract an electron from hydrocarbon, or because the resulting $\mathrm{Cu}(\mathrm{I})$ complex cannot be oxidized by oxygen.

In fact, some copper compounds, such as<smiles>[R]1[CH]Oc2c(sc3ccccc23)C=N1</smiles>

or

$$
(\text { RNHCSNHR' })_{2} \mathrm{Cu}(\mathrm{OAc})\left(\mathrm{R}, \mathrm{R}^{\prime}=\mathrm{Bz}, \mathrm{Ph}, \mathrm{PhCHMe}, \mathrm{p}-\mathrm{MeOC}_{6} \mathrm{H}_{4}\right)
$$

were found to inhibit oxidation by acting as scavengers of peroxy and alkyl radicals [12] [13]. On the contrary, copper chloride/crown ether complexes proved to be efficient oxidation catalysts, probably because crown ether protects both $\mathrm{Cu}(\mathrm{I})$ and $\mathrm{Cu}(\mathrm{II})$ from complexation with other ligands, making both valence states readily available for mediating electron transfer in red-ox processes.

In practice, oil oxidation can be effectively minimized by

1) use of antioxidants (to hinder the formation of radicals);

2) use of copper corrosion inhibitors (to hinder copper dissolution);

3) sealing and nitrogen-blanketing of transformers (to limit oxygen supply).

\subsection{Copper Corrosion and Dissolution}

Copper is the electrical conductor in many categories of electrical wiring. Transformers use copper winding wire. There exist several different types of chemical and electrochemical processes leading to copper dissolution:

1) Oxidative processes, e.g.

$$
\begin{gathered}
4 \mathrm{Cu}+\mathrm{O}_{2} \rightarrow 2 \mathrm{Cu}_{2} \mathrm{O} \\
\mathrm{Cu}+\mathrm{ROO}^{\bullet} \rightarrow \mathrm{Cu}^{+}+\mathrm{ROO}^{-}
\end{gathered}
$$

2) Reaction with acids in the presence of complexing agents or under oxidizing conditions,

$$
\begin{gathered}
\mathrm{Cu}+\mathrm{H}^{+}+\mathrm{L} \rightarrow \mathrm{CuL}^{+}+1 / 2 \mathrm{H}_{2} \\
2 \mathrm{Cu}+2 \mathrm{H}^{+}+[\mathrm{O}] \rightarrow 2 \mathrm{Cu}^{+}+\mathrm{H}_{2} \mathrm{O}
\end{gathered}
$$

where $\mathrm{L}$ denotes a chelating ligand, and $[\mathrm{O}]$ denotes an oxidants (it may be hydroperoxide, peroxyacid, oxygen, etc.)

3) Reactions with "corrosive sulphur" compounds, e.g.

$$
2 \mathrm{Cu}+\mathrm{S} \rightarrow \mathrm{Cu}_{2} \mathrm{~S}
$$




$$
\begin{gathered}
2 \mathrm{Cu}+\mathrm{H}_{2} \mathrm{~S}+\mathrm{O}_{2} \rightarrow \mathrm{Cu}_{2} \mathrm{~S}+\mathrm{H}_{2} \mathrm{O} \\
2 \mathrm{Cu}+\mathrm{RSH} \rightarrow \mathrm{Cu}_{2} \mathrm{~S}+\mathrm{RR}+\mathrm{H}_{2} \\
2 \mathrm{Cu}+\mathrm{RSSR}^{\prime} \rightarrow \mathrm{Cu}_{2} \mathrm{~S}+\mathrm{RR}+\mathrm{RR}^{\prime}+\mathrm{R}^{\prime} \mathrm{R}^{\prime}
\end{gathered}
$$

The above heterogeneous processes rarely display any specific stoichiometry and may yield a variety of products due to non-selective radical recombination.

4) Galvanic corrosion:

$$
\mathrm{Cu}-\mathrm{e}^{-} \rightarrow \mathrm{Cu}^{+}
$$

It should be noted that, based on the standard Red-Ox potentials, oxidation of water and many antioxidants present in oil is a thermodynamically preferential process. For instance, copper does not undergo electrochemical oxidation in aqueous solutions-it is rather water itself that is oxidized to $\mathrm{H}^{+}$and oxygen. However, in insulating oils, the concentration of other oxidizable species near the "anode" surface may be depleted to such an extent that the electrochemical oxidation of copper becomes possible. Other possible anodic processes include oxidation of phenols, carboxylic acids, carbohydrates, and other oxidizable compounds naturally occurring in, or added to, the insulating oil [14], e.g.

$$
\mathrm{RCOO}^{-}-\mathrm{e}^{-} \rightarrow \mathrm{RCOO}^{\bullet} \rightarrow \mathrm{RR}+\mathrm{CO}_{2}
$$

Corresponding cathodic processes may involve reduction of dissolved oxygen to hydroxide ions, reduction of aromatics cycles to anion-radicals, and reduction of disulphides to mercaptide ions, the latter being a potentially dangerous process. Because of an extremely low ion concentration of such species in insulating oil, strong electrode polarization is result. Hence, under alternating current conditions, very low conversion degrees are expected. Let's make some simple estimates. For instance, if the applied voltage is $1000 \mathrm{~V}$, the electrode surface $10 \mathrm{~cm}^{2}$, and the oil resistance $10 \mathrm{GOhm}$, the resulting current density will be $1000 \mathrm{~V} / 10^{10} \mathrm{Ohm}$ per $10 \mathrm{~cm}^{2}=$ $10^{-8} \mathrm{~A} / \mathrm{cm}^{2}$. Over a time of 30 years (which is $10^{9} \mathrm{~s}$ ), for instance, the equivalent Faraday ion flux will transfer 10C of electric charge per $\mathrm{cm}^{2}$, thereby removing or depositing $10 \mathrm{C} / 96,485 \mathrm{C} \mathrm{mol}^{-1} \approx 10^{-4} \mathrm{~mol}$ of ions per $\mathrm{cm}^{2}$. This corresponds to etching away a surface layer of copper having a thickness of $7 \mu \mathrm{m}$ only $\left(10^{-4} \mathrm{~mol} \cdot \mathrm{cm}^{-2} \times 64\right.$ $\mathrm{g} \cdot \mathrm{mol}^{-1} / 8.9 \mathrm{~g} \cdot \mathrm{cm}^{-3}=7 \times 10^{-4} \mathrm{~cm}$ ). The actual copper dissolution will be even less than that, because the Faraday current is going to be dominated by protons which have much higher mobility than copper ions.

The above estimates allow us to conclude that the fact that electrical stress speeds up copper release in transformers [15] is not likely related to electrochemical dissolution of copper as such but rather to anodic oxidation processes occurring at the surface of copper wire and leading to the formation of other aggressive species, such as oxygen and peroxides which may both attack copper chemically and trigger further chain reactions in the bulk. Besides that, the electrical stress in working transformers produces significant heat effects intensifying convective transport of reagents due to temperature gradients.

To minimize copper corrosion, a variety of metal passivators can be used. The most common in transformer oils are benzotriazole, mercaptobenzothiazole and their derivatives [16]-[18]. These compounds form dense and relatively impermeable surface films on the metal surface [19]-[21]. It doesn't seem to be realized, however, that adding a metal passivator only creates a kinetic but not a thermodynamic barrier to corrosion: the corrosion is going to proceed at a lower rate but the end state—a corroded metal—remains unchanged.

\subsection{Degradation of Paper}

The heat-induced ageing of paper has been of concern to the paper industry for decades, and as a consequence, a large number of studies on its mechanism and factors influencing the ageing kinetics have been carried out, providing rather complete picture of the phenomenon [22]-[29]. Thus, it is well known that the thermal ageing of paper becomes especially rapid as the ambient temperature rises to $120^{\circ} \mathrm{C}-140^{\circ} \mathrm{C}$. For isolated bleached kraft pulps, the degree of ageing was reported to be nearly the same in nitrogen and oxygen atmospheres. However, for paper insulation in oil-filled transformers, the presence of oxygen has an accelerating effect on paper degradation [1]. The auto-oxidation of cellulose by atmospheric oxygen is believed to proceed through a free radical mechanism that generates peroxides and, subsequently, carboxylic acid groups [30]. Transition metal ions, specifically copper, have a pronounced catalytic effect on the oxidation.

Among the major factors having an adverse effect on the thermal stability of paper were mentioned humidity, acidity, and the presence of transitional metal ions, specifically copper and iron [4] [22] [26] [27]. Hydrolysis 
results in discoloration of paper and in a lowering of the degree of polymerization of the cellulose chain, and, consequently, a loss in paper strength [2]-[4] [23].

One may hypothesize that at the conditions such as in power transformers: elevated temperatures and presence of radical species, cellulose in insulating paper undergoes a sequence of depolymerization, oxidation and dehydration reactions, e.g.

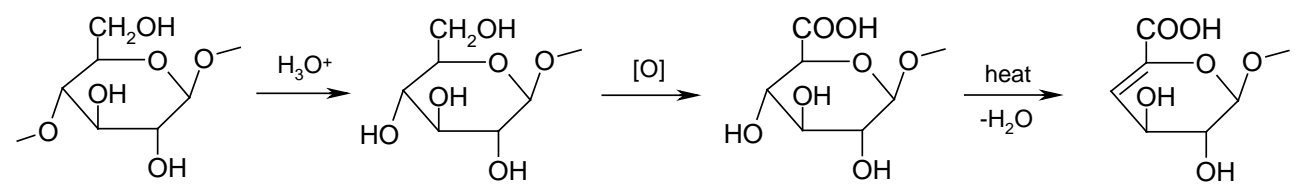

producing monosaccharides and certain unsaturated reactive intermediates, such as hexenuronic acid. Some quantities of hexenuronic acid are always present in kraft pulps used for the insulation as a result of the conversion of 4-O-methyl-D-glucoron acid side-groups of the xylan backbone under alkaline conditions used for the pulp production. As was shown previously [22], hexenuronic acid groups are involved in further complex transformations yielding furanic structures in the end, e.g.

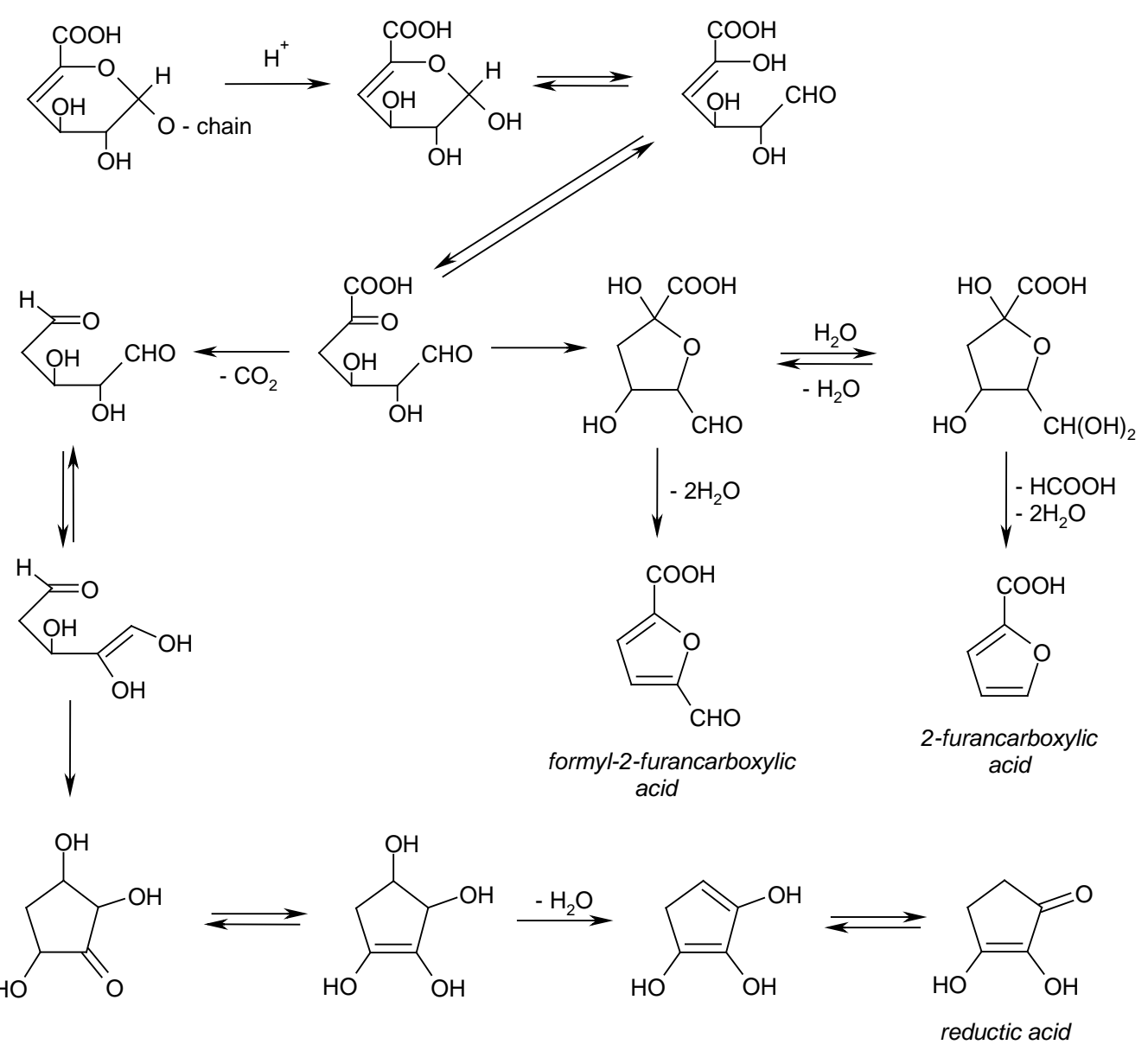

As a result, furanic structures are invariably present among carbohydrate degradation products in high-temperature processes such as wood pyrolysis, steam treatment, etc. [31]-[33]. The formation of furanic compounds, mainly furfural and hydroxy methyl furfural, is considered as an indication of the degradation of paper insulation in power transformers [24] [25] [28] [29].

Deeper oxidation of cellulose yields a number carboxylic acids [27] (see Figure 2), many of which may act as complexing agents for copper. 


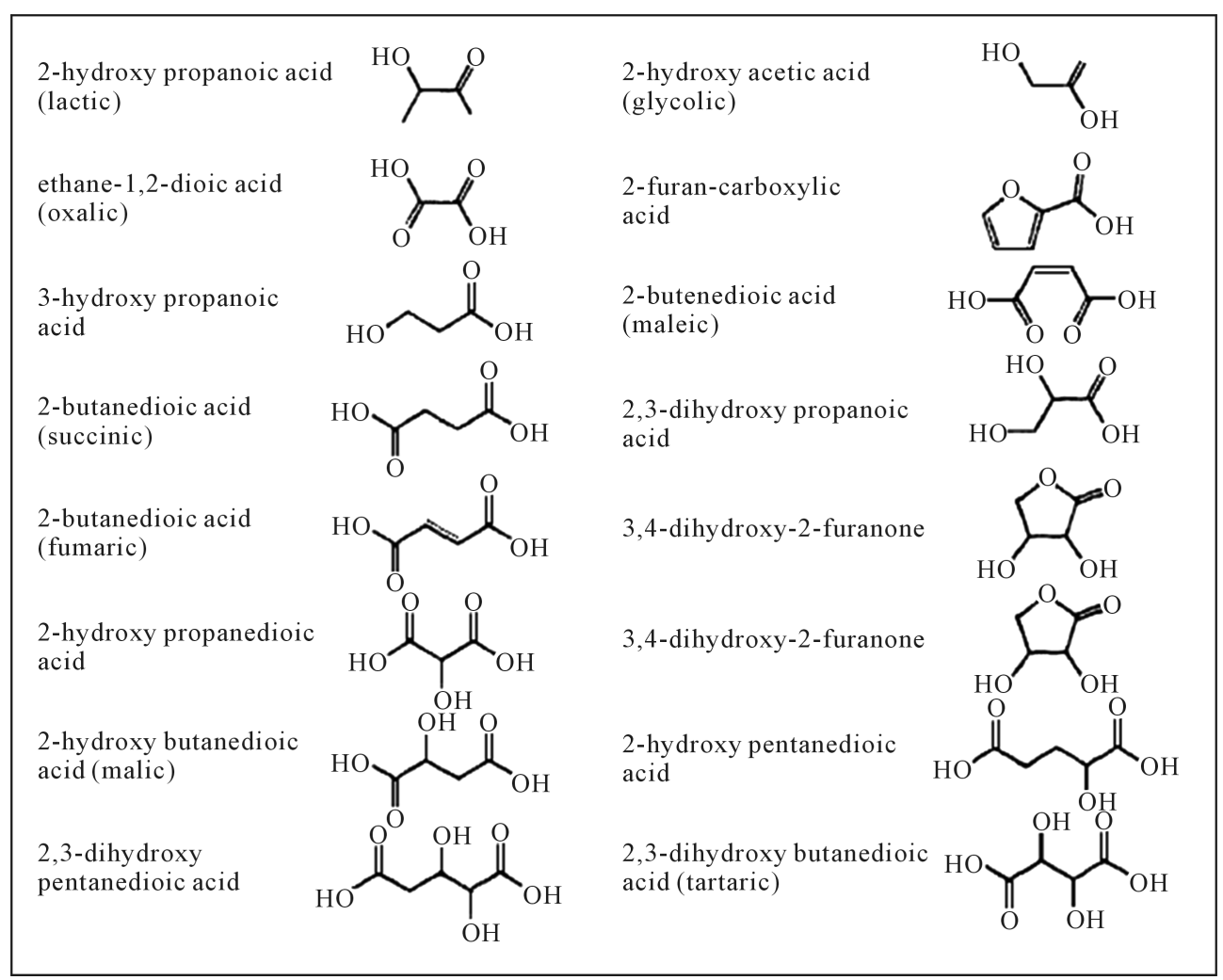

Figure 2. Carboxylic acids produced as a result of oxidative degradation of paper [27].

\subsection{Water in Transformers}

Water contamination of transformer oil is one the most common product quality deviations. The presence of water in oil compromises the insulating capacity of the oil/paper system, as can be demonstrated by a substantial drop in the break-through voltage and an increase in the dissipation factor of oil. Accumulation of water in transformer occurs mostly due to the ingress of atmospheric humidity and due to oxidation and dehydration reactions of oils and paper. Apart from degrading the insulation, water may also promote corrosion and bacterial attack. As the industrial experience shows, the problems become especially severe if the concentration of water in oil increases to such an extent that the phase separation occurs. In this case, water tends to condense inside the paper insulation or at the bottom of the transformer. Since the aqueous phase is polar, it selectively accumulates other polar substances, such as carboxylic acids and salts, creating ion-conductive bridges within the insulating material. This increases the risk of short-cuts causing a total transformer failure.

Understanding of the risks associated with the presence of water in transformers has led the development of technical solutions to avoid such problems. In most cases, adsorption, filtration or physical separation of water and other impurities, including sludge and colloidal matter, is attempted [34]-[38].

\section{Experimental}

Two commercially available mineral insulating oils, an inhibitor-free transformer oil Renolin Eltec (FUCHS, density $0.868 \mathrm{~g} \cdot \mathrm{cm}^{-3}$ at $20^{\circ} \mathrm{C}$; viscosity $10 \mathrm{cSt}$ at $40^{\circ} \mathrm{C}$; total acid number $<0.01 \mathrm{mg} \mathrm{KOH} / \mathrm{g}$; pour point $<-48^{\circ} \mathrm{C}$ ) and an inhibited transformer oil T-1500 (Bashneft, density $0.885 \mathrm{~g} \cdot \mathrm{cm}^{-3}$ at $20^{\circ} \mathrm{C}$; viscosity $11 \mathrm{cSt}$ at $40^{\circ} \mathrm{C}$; total acid number $<0.01 \mathrm{mg} \mathrm{KOH} / \mathrm{g}$; pour point $<-45^{\circ} \mathrm{C}$ ) and paper wrapped rectangular copper wire (Cu-ETP, DIN 46434) for power transformers were used for the experiments on copper release kinetics.

Copper wire had three layers of insulating kraft paper and was cut into pieces of $10 \mathrm{~cm}$ length, so that all samples used in the ageing tests had the same dimensions: length $100 \mathrm{~mm}$, width $6 \mathrm{~mm}$, thickness $1.2 \mathrm{~mm}$. The samples were placed in glass vial containing $50 \mathrm{ml}$ of oil; two pieces per vial. Vials were thermostated at a desired temperature $\left(150^{\circ} \mathrm{C}\right)$. If needed, the vials were closed by ground-glass stoppers to minimize air intake; or 
air intake was controlled by bubbling air through the oil at a constant rate of $0.1 \mathrm{~L} / \mathrm{h}$. Aliquots of oil were sampled at intervals for testing.

In order to study the effect of oxidation products on copper release kinetics, $1 \mathrm{~g}$ of kraft paper impregnated by oil was aged for 2 weeks in an open vial placed in an oven at $150^{\circ} \mathrm{C}$. The resulting dark-brown product represents a crude mixture of cellulose and oil degradation products including furaldehyde, furancarboxylic acid, and a great number of other compounds. A small amount of the product (ca $0.5 \mathrm{~mL}$ ) was added to $50 \mathrm{~mL}$ of fresh oil. Copper release from a bare copper wire was measured in a sealed-tube experiment at $150^{\circ} \mathrm{C}$ and compared to the data obtained for pure oil under the same conditions.

\section{Results and Discussion}

\subsection{Barrier Properties of Paper Insulation}

The paper insulation present at the surface of copper wire creates a barrier to mass and heat transport processes. As can be seen in Figure 3, the copper release rate increases significantly if paper insulation is removed. In the sealed-tube experiment, inhibited and inhibitor-free oils post similar results. While using a thicker layer of paper certainly enhances its insulation capability, it also impairs the efficiency of heat removal. Hence, a compromise needs to be found.

\subsection{Role of Early Oxidation Products in Copper Dissolution}

As mentioned in the overview of the chemistry of insulation ageing processes, many oxidation products accumulating in oil as the ageing progresses are good complexing agents for copper ions. Therefore, it is logical to expect that copper dissolution rate increases with increasing "corrosiveness" of oil. This has been directly confirmed by comparing the copper release rates in fresh oil and in oxidized oil contaminated by a crude mixture of oil and paper degradation products, see Figure 4.

\subsection{Effect of Additives on Copper Dissolution}

So far, effects of common inhibitors on copper release kinetics have not been sufficiently studied.

Antioxidants are often used in oil formulations for improving the oxidation stability of the product [39] [40]. Dibutyl para-cresol (DBPC) is an effective radical scavenger, commonly used in inhibited oils. Another common additive is a copper corrosion inhibitor, such as 5-methyl-1,2,3-benzotriazole or tolutriazole (TTA). According to Maina et al. [41] and Amaro et al. [42], some commercial products might have contained DBPC in

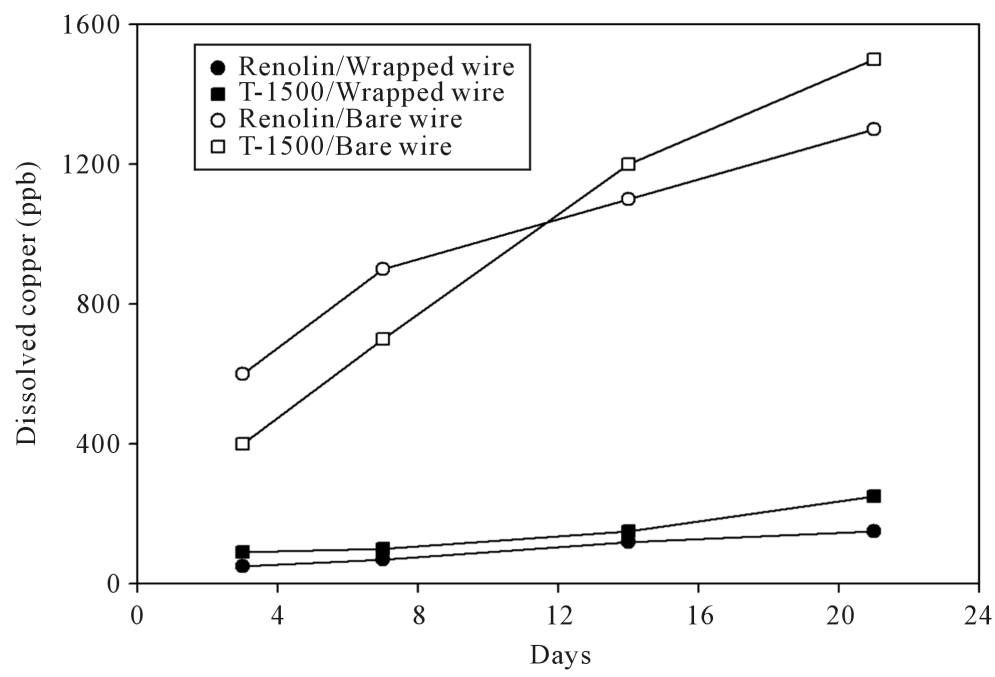

Figure 3. Barrier properties of the paper layer: the copper release kinetics from bare and paper-wrapped copper wire are compared. Sealed-tube experiment at $150^{\circ} \mathrm{C}$. The characteristic copper fluxes are ca $1 \times 10^{-8} \mathrm{~g} \cdot \mathrm{m}^{-2} \cdot \mathrm{s}^{-1}$ for the paper-wrapped wire and ca $1.0 \times 10^{-9} \mathrm{~g} \cdot \mathrm{m}^{-2} \cdot \mathrm{s}^{-1}$ for the bare wire. 




Figure 4. Effect of paper degradation products on oil corrosiveness towards copper (sealed-tube experiment with bare copper wire, $150^{\circ} \mathrm{C}$ ).

combination with another undeclared additive, dibenzyldisulphide (DBDS). DBDS is an effective antioxidant of peroxide decomposer type, acting synergistically with DBPC and significantly improving the oxidation stability of the oil. Unfortunately, DBDS was found to be extremely copper-corrosive [41]-[44], bringing about far more serious disruptions of transformer operation than oil oxidation can even do.

In sealed-tube experiments with restricted air ingress, the presence of DBPC has no effect on copper dissolution, while the presence of DBDS causes a significant increase in copper release rate, supporting the early reports that DBDS is corrosive towards copper.

In open-tube experiments under continuous air flow, the situation changes dramatically. First, much greater copper release rates are observed. Second, the presence of the phenolic antioxidant, DBPC, effectively hinders copper dissolution until the antioxidant reserve gets depleted by oxidation. Third, DBDS seems to become less corrosive in this case as it undergoes partial oxidation and the resulting sulfones are not copper-corrosive. In this connection, it should be pointed out that, while the presence of oxygen favours copper dissolution and higher acidity is normally associated with higher copper contents, it may not be the case when a sufficient amount of DBDS is present: even though oil is then better protected against oxidation, as reflected in a low total acid number of the aged oil, copper becomes vulnerable to corrosive attack by DBDS (see Figure 5).

\subsection{Copper Release Kinetics}

Copper dissolution in oil-filled transformers involves a number of reaction pathways. The fact that the dissolution rate increases under oxidizing conditions, e.g. in the presence of atmospheric oxygen, suggests that the metal oxidation plays an important role here. However, the dissolution rate is non-zero even in an inert atmosphere. This can be attributed to the dissolution of oxide films present at the surface of metal from the beginning. Based on ellipsometric data available in literature, the thickness of the oxide layer at the surface of copper is around $100 \mathrm{~nm}$ [45]. The surface area of the copper wire in our experiments was $2 \times(0.006+0.001) \times 0.01=$ $2.8 \times 10^{-3} \mathrm{~m}^{2}$, and hence, the surface layer contains ca $3 \times 10^{-10} \mathrm{~m}^{3}$ of copper oxide.

Given the density of this substance of ca $6.4 \times 10^{3} \mathrm{~kg} / \mathrm{m}^{3}$, the mass of the oxide film should be around $2 \mathrm{mg}$. The complete dissolution of such a film would produce as much as $20 \mathrm{ppm}$ of copper in our experiments, which is one to three orders of magnitude greater than the actual concentrations measured (in the ppb range). This proves that, during the experimental time, the initial oxide film has not yet been dissolved completely. What is often considered as the reaction of metal copper in reality appears to be the reaction of copper oxide.

The question arises why the presence of oxygen accelerates the "copper" dissolution once the metallic surface remains buried under the oxide film. The explanation is rather simple: First, the oxide film is not absolutely impermeable-copper oxide does not form passivating films as does, for example, alumina. Second, more importantly, the concentration of dissolved oxygen is directly proportional to the partial pressure of oxygen in the 


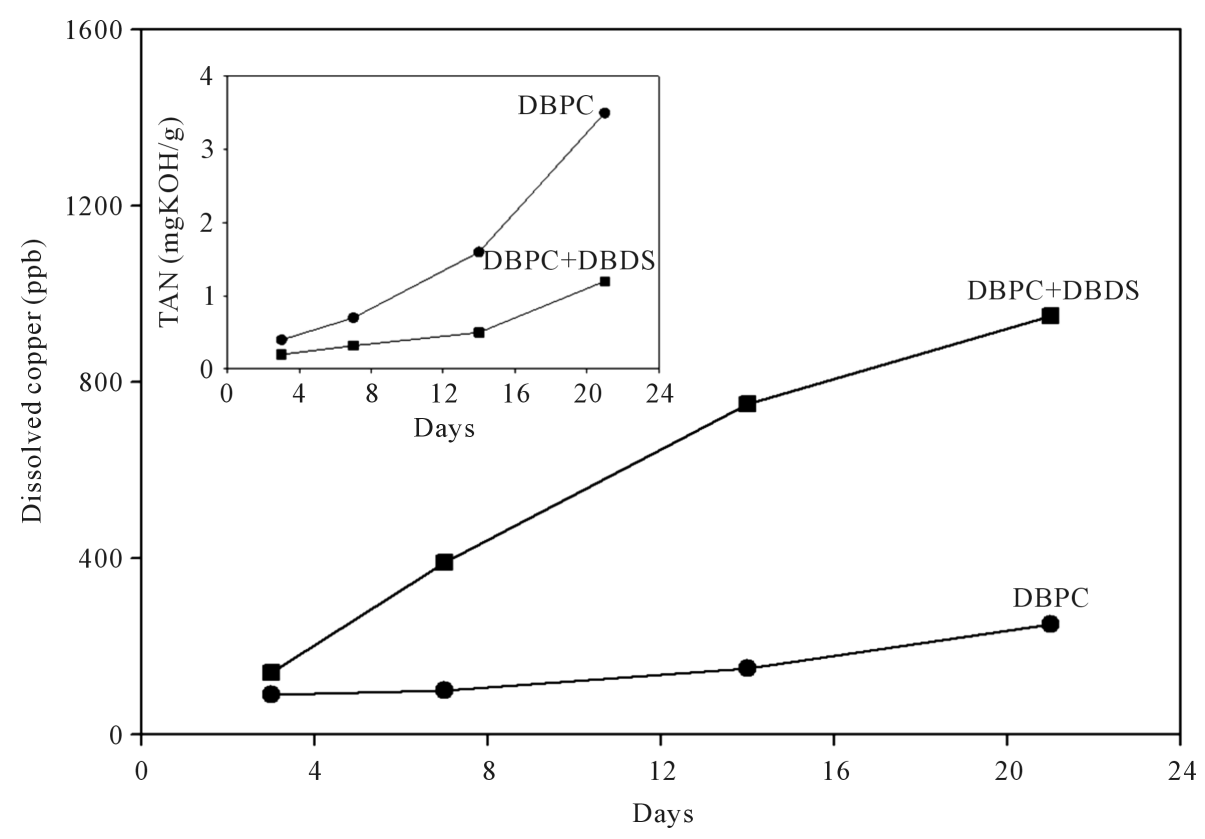

Figure 5. Effect of DBDS on copper release and oil oxidation kinetics. (Open-tube experiments with a DBPC-inhibited commercial product T-1500 and paper-wrapped copper wire at $150^{\circ} \mathrm{C}$, the concentration of DBDS was $\left.500 \mathrm{ppm}\right)$.

surrounding atmosphere (air or a nitrogen blanket). In free-breathing transformers, it may reach 40 - 50 ppm; and in sealed transformers it still may be a few ppm. Since the rate of oil oxidation increases with increasing the oxygen concentration, more oxidation products capable of etching the oxide film is formed per unit time, and hence, the copper release rate also increases.

Let's formulate the corresponding kinetic equations for several feasible kinetic scenarios.

Scenario 1: Let the dissolved copper be generated by dissolution of the oxide film. In this case, the flux of dissolved copper at the $x=0$ is given by

$$
J(t)=J_{\max }\left(1-\frac{c(0, t)}{c_{s}}\right)
$$

where $J_{\max }$ is the maximum flux achieved under no diffusional restrictions, $c_{s}$ is the saturation concentration of copper oxide in hydrocarbon media, and $c(0, t)$ is the actual concentration of copper near the surface (see Figure 6). The concentration profile of copper within the insulation paper, i.e. in the range $0<x<L$, is given by the diffusion equation,

$$
\frac{\partial c}{\partial t}=D \frac{\partial^{2} c}{\partial x^{2}}
$$

with the boundary conditions

$$
-\left.D \frac{\mathrm{d} c}{\mathrm{~d} x}\right|_{x=0}=J(t) ; c(L, t)=C_{b}(t) ; c(x, 0)=\xi(x)(0<x<L)
$$

where $D$ is the diffusion coefficient of copper in paper, $C_{b}(t)$ is the concentration of copper in the oil phase and $\xi(x)$ is the initial concentration profile of copper within the paper layer at the beginning of the experiment. Adding the mass conservation requirement,

$$
-\left.\int_{0}^{t} D \frac{\mathrm{d} c}{\mathrm{~d} x}\right|_{x=L} \mathrm{~d} t=\frac{V}{S} C_{b}(t)
$$

where $V$ is the volume of oil and $S$ is the surface area of the copper wire, one can calculate the copper release kinetics. 




Figure 6. Mass transport processes occurring in the paper-oil insulation system during the ageing process.

If dissolution goes rapidly, so that the saturation concentration is constantly maintained near the wire surface (i.e. $c(0, t)=c_{s}$ ), the diffusion profile can be approximated by that for diffusion from a distributed source. The saturation is achieved over a time of $D\left(c_{s} / J_{\max }\right)^{2}$ and is localized within a layer of thickness $D c_{s} / J_{\max }$. Afterwards,

$$
\frac{c_{s}-c(x, t)}{c_{s}} \simeq \operatorname{erf} \frac{x}{2 \sqrt{D t}}\left(t>D\left(c_{s} / J_{\max }\right)^{2} ; L>x>D c_{s} / J_{\max }\right)
$$

i.e. one has a descending diffusional profile with the concentration of copper declining within the subsequent paper layers.

If the diffusion coefficient is, for example, $10^{-10} \mathrm{~m}^{2} / \mathrm{s}$ and the thickness of the paper insulation $1 \mathrm{~mm}$, it would take just a few hours for diffusion front to advance to the top paper layer and copper to start to be released into the adjacent oil phase.

Further, if the distribution of copper within the insulation layer separating two adjacent copper wires is concerned, a U-shaped concentration profile is to be expected,

$$
c(x, t)=\frac{c_{s}}{2}\left\{\operatorname{erfc} \frac{L-x}{2 \sqrt{D t}}+\operatorname{erfc} \frac{L+x}{2 \sqrt{D t}}\right\}
$$

and has been observed experimentally elsewhere [46].

If, on the contrary, dissolution goes slowly, so that there is only a little change in concentration of dissolved copper over a time of $L^{2} / D$, a nearly linear concentration profile will be maintained,

$$
c(x, t)=C_{b}(t)+\frac{J_{\max }}{D}(L-x)
$$

for a copper wire in contact with the oil phase, and a uniform copper concentration profile will be maintained in the insulation between the adjacent copper wires,

$$
c(x, t) \simeq \frac{t J_{\max }}{L}
$$

If the binding of copper to the surface of paper is taken into account, the form of the concentration profile will not change, but the effective diffusion coefficient will decrease to $D /(1+K)$, where $K$ is the corresponding adsorption constant.

Scenario 2: The copper release is mediated by a corrosive substance present in the oil phase from the beginning. Examples of such substances are "corrosive sulphur compounds", e.g. DBDS.

From a mathematical viewpoint, this is a more complex situation since multiple fluxes are involved. The Maxwell-Stefan formalism is an appropriate tool for describing the mass transport in this case. Let $c_{c}$ and $N_{c}$ denote the molar concentration and the molar flux of the corrosive substance diffusing towards the metal surface, and $c_{p}$ and $N_{p}$ denote the same for the corrosion product diffusing in the opposite direction, towards the oil phase. 
In this case, the governing equations are as follows,

$$
-\frac{\partial c_{i}}{\partial x}=\sum_{j \neq i} \frac{x_{j} N_{i}-x_{i} N_{j}}{D_{i j}}+\frac{N_{i}}{D_{i}^{K}}
$$

Notice that there are two sorts of the diffusion coefficients: $D_{i j}$ describe the cross-interaction between the fluxes of the corrosive substance and the corrosion products, and $D_{i}^{K}$, referred to as the Knudsen diffusion coefficient, describes the interaction with the medium (insulating paper) through which the diffusion takes place.

The above equations must be complemented by a kinetic equation describing the generation of the corrosion product at the surface. In general, one may distinguish:

1) diffusion-controlled kinetics;

2) activation-controlled kinetics;

3) mixed kinetics.

Let's briefly analyse all the three cases:

1) In the diffusion-controlled case, all the corrosive substance that penetrates to the metal surface is immediately converted into the corrosion product, which migrates back into the oil phase. As shown before, the characteristic diffusion time through a $1 \mathrm{~mm}$ thick layer of insulating paper does not exceed a few hours. It is during this initial interval of time that the copper release will reveal the classical diffusion kinetics with the amount released being proportional to square-root of time. Afterwards, the corrosive substance is going to be consumed at a constant rate of $D c_{c} / L$. Accordingly, the amount of copper released increases linearly with time- this may be mistakenly considered as a sign of an activation-controlled process. Indeed, by hindering the reagent transport, the paper layer acts as a kinetic barrier to copper release.

If, for instance, $D=10^{-10} \mathrm{~m}^{2} \cdot \mathrm{s}^{-1} ; L=1 \mathrm{~mm}$ and $c_{c}=1 \mathrm{~mol} \cdot \mathrm{m}^{-3}$ (typical at treat levels of around $100 \mathrm{ppm}$ ), the consumption rate will be around $10^{-7} \mathrm{~mol} \cdot \mathrm{m}^{-2} \cdot \mathrm{s}^{-1}$. The corresponding copper release will be then of the order of $10^{-5} \mathrm{~g} \cdot \mathrm{m}^{-2} \cdot \mathrm{s}^{-1}$. In our experiments, the exposed surface area was $3.2 \times 10^{-3} \mathrm{~m}^{2}$, the oil volume $50 \mathrm{~mL}$. Hence, in the diffusion-controlled regime-provided that the corrosive substance and the corrosion product have comparable diffusivities - the expected copper release rate should be around $500 \mathrm{ppb}$ per day, 50 times exceeding the characteristic values measured experimentally (ca $10 \mathrm{ppb}$ per day). The lower-than-expected release rate may be attributed to 1) the binding of the corrosion product by the insulating paper, as this causes a drop in diffusivity; and to 2) the existence of an activation barrier for the conversion of the corrosive substance into the corrosion product.

To figure out the actual cause, experiments were carried out with a copper wire stripped of the insulation paper and DBDS as a copper-corrosive substance. For bare copper wire, the copper release rate was almost one order of magnitude greater than for paper-covered wire, thus suggesting that the corrosion product-copper sulphide in the case in hand-was retained by paper.

2) In the activation-controlled case, the reaction rate at which the corrosive substance is converted into the corrosion product depends on the local concentration of the reagents and reaction products in the conversion zone. For instance, if diffusional limitations are eliminated by agitation and the corrosion product does not form a passive surface film, the conversion rate often follows the simple first-order kinetic equation,

$$
\frac{\mathrm{d} c_{c}}{\mathrm{~d} t}=-k c_{c}
$$

If a passive surface film is formed, the second-order kinetic is more common,

$$
\frac{\mathrm{d} c_{c}}{\mathrm{~d} t}=-k c_{c}\left(c_{p}^{\text {sat }}-c_{p}\right)
$$

where $c_{p}^{\text {sat }}$ indicates the saturation concentration of the corrosion product. Usually, $c_{p}^{\text {sat }} \approx 1 / V_{M}$, where $V_{M}$ is the molar volume of the corrosion product. Once the saturation concentration is reached, the conversion rate virtually goes down to zero. Examples of such reactions are the reaction of steel with concentrated sulphuric acid, in which case a passive film of iron sulphate protect steel from acid attack, and the reaction of aluminium with oxygen, in which case a surface film of alumina protects the metal from oxygen attack. DBDS, however, does not form a protective film on copper and the corrosion will proceed until complete conversion of DBDS into copper sulphide. Surface films produced by metal passivators of TTA type appears to be semi-permeable, as significant metal release are observed. 
3) In the mixed kinetic regime, which is most common in practice, both diffusional and activation limitations play a role. The corrosive substance diffusing to the metal surface is only partially converted into the corrosion product. In this case, the Stefan-Maxwell mass transport Equations (9) should be coupled with appropriate boundary conditions describing the surface reaction kinetics, e.g.

$$
\begin{aligned}
\frac{\mathrm{d} \theta_{c}}{\mathrm{~d} t} & =\left[k_{c}^{+} c_{c}(0, t)\left(1-\theta_{c}-\theta_{p}\right)-k_{c}^{-} \theta_{c}-k_{c \rightarrow p} \theta_{c} \theta_{p}\right] \exp \left(-\lambda_{c} \theta_{c}-\lambda_{c p} \theta_{c} \theta_{p}\right) \\
\frac{\mathrm{d} \theta_{p}}{\mathrm{~d} t} & =\left[k_{p}^{+} c_{p}(0, t)\left(1-\theta_{c}-\theta_{p}\right)-k_{p}^{-} \theta_{p}+k_{c \rightarrow p} \theta_{c} \theta_{p}\right] \exp \left(-\lambda_{p} \theta_{p}-\lambda_{c p} \theta_{c} \theta_{p}\right)
\end{aligned}
$$

where $\theta_{i}(i=c, p)$ are the degrees of surface filling by the adsorbed corrosive substance (subscript $c$ ) and the corrosion product (subscript $p$ ), and $k_{i}^{+}$and $k_{i}^{-}(i=c, p)$ are the adsorption and desorption rate constants for the corrosive substance and for the corrosion product, respectively; $k_{c \rightarrow p}$ is the conversion rate constant; and $\lambda_{c}, \lambda_{p}$ and $\lambda_{c p}$ are empirical parameters, taking into account the energy of lateral interactions between the corresponding adsorbed species.

The above kinetic equations should be complemented by the mass conservation constraint

$$
\frac{\mathrm{d}}{\mathrm{d} t}\left[\Gamma_{c}^{\text {sat }} \theta_{c}+\Gamma_{p}^{\text {sat }} \theta_{p}\right]=N_{c}(0, t)-N_{p}(0, t)
$$

which demands that the change in the total amount of substance adsorbed to the surface be equal to the difference between the incoming and outgoing fluxes.

The examples of reactions following the abovementioned kinetics equations are those of etching the surface oxide films by carboxylic acids, sulfonic acids, benzotriazoles, and other surface-active organic compounds capable of forming complexes with copper, e.g.

$$
2 \mathrm{RSO}_{3} \mathrm{H}+\mathrm{Cu}_{2} \mathrm{O} \rightarrow 2 \mathrm{RSO}_{3} \mathrm{Cu}+\mathrm{H}_{2} \mathrm{O}
$$

Scenario 3: The copper dissolution occurs primarily due to reaction with a corrosive substance which is produced in oil in the course of ageing. Examples of such corrosive substances are carboxylic, hyrdoxycarboxylic and $\beta$-keto acids originating either from paper or from oil, as well as hydroperoxides originating from oil oxidation. These substances, in combination, can etch both copper oxide and metallic copper according to the reactions,

$$
\begin{gathered}
\mathrm{Cu}_{2} \mathrm{O}+2 \mathrm{H}^{+} \rightarrow 2 \mathrm{Cu}^{+}+\mathrm{H}_{2} \mathrm{O} \\
2 \mathrm{Cu}+\mathrm{ROOH}+2 \mathrm{H}^{+} \rightarrow 2 \mathrm{Cu}^{+}+\mathrm{ROH}+\mathrm{H}_{2} \mathrm{O}
\end{gathered}
$$

The oxidation rate at a given temperature is known to increase with increasing the partial pressure of oxygen. Under the normal conditions, mineral oil dissolves 40 to $50 \mathrm{ppm}$ of oxygen. If one runs a sealed-tube experiment and the dissolved oxygen is entirely converted into carboxylic groups, the resulting acid concentration will be 1 - $2 \mathrm{mmol} \cdot \mathrm{dm}^{-3}$, corresponding to a total acid number around $0.06-0.12 \mathrm{mgKOH} / \mathrm{g}$. In practice, the total acid number of oils aged in a sealed-tube experiment is always less than the above estimate because of the formation of oxidation products other than carboxylic acids.

In a sealed-tube experiment, the concentration of a corrosive substance produced as a result of oil oxidation will increase with time according to the equation,

$$
c_{c}(t)=c_{c}^{\max }[1-\exp (-k t)]
$$

where $k$ is the oxidation rate constant and $c_{c}^{\max }$ is the maximum amount of the corrosive substance a given amount of oxygen can produce.

In an open-tube experiment, when the concentration of dissolved oxygen is maintained constant by e.g. bubbling air through oil, the concentration of a corrosive substance produced as a result of oil oxidation will increase with time according to the equation,

$$
c_{c}(t)=k x_{\mathrm{O}_{2}} t
$$

where $x_{\mathrm{O}_{2}}$ is the volume fraction of oxygen in air.

If copper dissolution were caused by a corrosive substance generated by oil oxidation, the copper release rate would have increased with time, producing a parabolic rather than a linear release vs time kinetic curves. This 
does not appear to be the case. Even though copper release rates measured under oxidizing conditions (air) are found to be consistently higher that those measured under neutral conditions (nitrogen), the concentration of dissolved copper increases approximately linearly with time in both cases. Therefore, there must exist another kinetic step-e.g. desorption of reacted copper-that limits the copper release rate.

The typical kinetic curves corresponding to above-mentioned kinetic scenarios are compared in Figure 7.

It should be noted that the dissolved copper tends to concentrate in sludge, the amount of which increases in the course of oxidation. This explains why the copper content in oil may eventually pass through a maximum and then start to decline- -this reflects the complex interplay of the copper dissolution and the sludge precipitation processes.

\subsection{Estimation of the "Activation Energy" for the Copper Release Process}

In fact, it is inappropriate to talk about the activation energy of a multi-pathway process: as has been pointed out in the previous sections, there are a number of reaction pathways leading to copper accumulation in oil. Let, for instance, there be two parallel reactions, having the activation energies $E_{1}$ and $E_{2}$, respectively. Then, the relative yields of those reactions change with temperature as $\exp \left[-\left(E_{1}-E_{2}\right) / R T\right]$. In other words, the apparent "activation energy" of the entire process changes with temperature, making the simple Arrhenius law inapplicable. Since, in the present study, no attempts have been made to delineate individual contributions of various ageing reactions, only general observations regarding the changes in the copper release kinetics with temperature are reported:

1) Oxidative versus non-oxidative cases. In sealed-tube experiments, the copper flux increases by about 10 times on increasing the temperature from $20^{\circ} \mathrm{C}$ to $120^{\circ} \mathrm{C}$. In open-tube experiments, the equivalent flux increase is one order of magnitude greater. This suggests that, under the oxidative conditions, the copper release is significantly influenced by another chemical process with a higher activation energy. This empirical finding well conforms to the fact that the activation energy for the hydrocarbon oxidation initiation reaction (ca $40 \mathrm{kcal} \cdot \mathrm{mol}^{-1}$ according to [40]) is much greater than the activation energy for typical complexation and diffusion processes (usually, 1 to $10 \mathrm{kcal} \cdot \mathrm{mol}^{-1}$, see e.g. [47] [48]).

2) Wrapped wire versus bare wire. The removal of paper from the copper wire somewhat reduces the "activation energy" of the copper release process. This is what is expected for a sequential process including of two or more activated stages: Indeed, the removal of paper eliminates the diffusion barrier and precludes the adsorption of copper onto the paper surface.

\section{Conclusions}

1) The ageing of the oil-paper insulation system in oil-immersed electrical current transformers involves several inter-related reaction pathways, the most important of which are a) thermal ageing of the insulating paper;

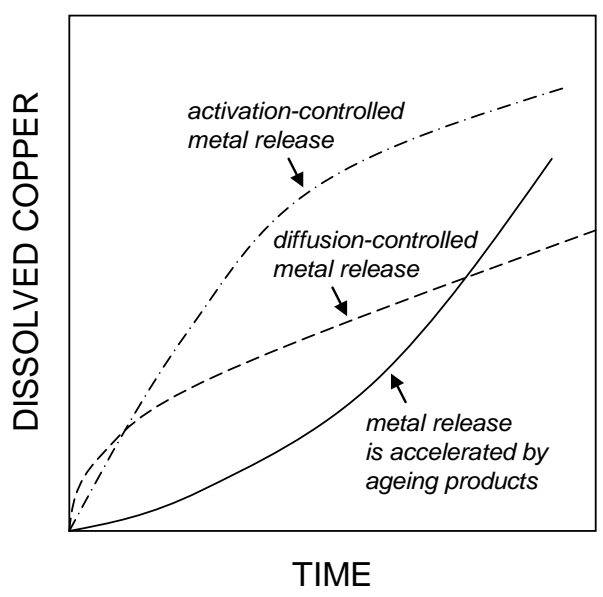

Figure 7. Characteristic copper release curves for various kinetic scenarios. 
b) oxidation of the oil; and c) corrosion of copper winding followed by accumulation of corrosion products within the insulating paper layer.

2) The relative importance of those processes varies greatly depending on the operational conditions, the base oil quality, the additive package, and the transformer design. For instance, in highly loaded or overloaded transformers, operated at a high temperature, the thermal degradation of the insulating paper is unavoidable, no matter which oil and additives are used. In normally loaded open-breathing transformer, oil oxidation will occur. Acidic oil oxidation products accumulating in oil not only affect the dissipation factor and insulating capability of the oil itself but also promote depolymerization of cellulose and etch metal. In this case, using inhibited oils containing antioxidants remedies the problem: inhibited oils are found to perform much better than non-inhibited ones in the majority of tests. However, it should be kept in mind that additivation is sometimes done for a mere purpose of passing certain unified quality standards_-often lacking foresight of actual application scenarios. As a result of that, an additive which proved to be highly efficient in open breathing transformers may not have the same effect when used in sealed-type transformers. Ideally, additivation strategies should match enduse scenarios.

3) Copper release kinetics are strongly influenced by oil quality, additives and ageing conditions. Unsaturated hydrocarbons, oil oxidation products and paper degradation products all play a role in copper transportation. The mixed diffusion-activation controlled kinetic mechanism is applicable in most cases. Use of appropriate antioxidants, preferably in combination with a metal inhibitor, allows one to effectively minimize copper dissolution, specifically in open-vial experiments and in corrosive environment. The presence of water in oil slightly accelerates copper release, due probably to faster cellulose degradation in humid environment.

\section{References}

[1] Emsley, A.M., Xiao, X., Heywood, R.J. and Ali, M. (2000) Degradation of Cellulosic Insulation in Power Transformers. IEE Proceedings: Science, Measurement and Technology, 147, 110-114. http://dx.doi.org/10.1049/ip-smt:20000259

[2] Lundgaard, L.E., Hansen, W., Linhjell, D. and Painter, T.J. (2004) Aging of Oil-Impregnated Paper in Power Transformers. IEEE Transactions on Power Delivery, 19, 230-239. http://dx.doi.org/10.1109/TPWRD.2003.820175

[3] Lundgaard, L.E., Hansen, W. and Ingebrigtsen, S. (In Press) Ageing of Mineral Oil Impregnated Cellulose by Acid Catalyses. IEEE Transactions on Power Delivery.

[4] Shroff, D.H. and Stannett, A.W. (1985) A Review of Paper Aging in Power Transformers. IEE Proceedings C: Generation, Transmission and Distribution, 132, 312-319. http://dx.doi.org/10.1049/ip-c.1985.0052

[5] Melchiore, J.J. and Mills, I.W. (1965) The Role of Copper during the Oxidation of Transformer Oils. Journal of the Electrochemical Society, 112, 390-395. http://dx.doi.org/10.1149/1.2423555

[6] Lund, H. and Hammerich, O., Eds. (2000) Organic Electrochemistry. Marcel Dekker, New York.

[7] Guan, R., Hashimoto, H. and Yoshida, T. (1984) Electron-Microscopic Study of the Structure of a Metastable Oxide Formed in the Initial Stage of Copper Oxidation. I. Copper Oxide $\left(\mathrm{Cu}_{4} \mathrm{O}\right)$. Acta Crystallographica, Section B: Structural Science, B40, 109-114. http://dx.doi.org/10.1107/S0108768184001841

[8] Guan, R., Hashimoto, H. and Kuo, K.H. (1984) Electron-Microscopic Study of the Structure of Metastable Oxides Formed in the Initial Stage of Copper Oxidation. II. $\mathrm{Cu}_{8} \mathrm{O}$. Acta Crystallographica, Section B: Structural Science, B40, 560-566. http://dx.doi.org/10.1107/S010876818400269X

[9] Guan, R., Hashimoto, H. and Kuo, K.H. (1985) Electron-Microscopic Study of the Structure of Metastable Oxides Formed in the Initial Stage of Copper Oxidation. III. Copper Oxide $\left(\mathrm{Cu}_{64} \mathrm{O}\right)$. Acta Crystallographica, Section B: Structural Science, B41, 219-225. http://dx.doi.org/10.1107/S0108768185002026

[10] Yanagisawa, K., Saito, M., Matsunaga, A. and Nakamura, Y. (1990) Analysis of Radicals and Copper(I) Ion Formed in Initial Oxidation Stage of Insulating Oils. Sekiyu Gakkaishi, 33, 378-382. http://dx.doi.org/10.1627/jpi1958.33.378

[11] Cotton, F.A. and Wilkinson, G. (1988) Advanced Inorganic Chemistry. 5th Edition, Wiley, New York.

[12] Smurova, L.A. and Gagarina, A.B. (1985) Effectiveness of the Inhibiting Action of Copper(II) Bis[2-[(Phenylimino)Methylene]Benzothiophen-3-Olate] in the Oxidations of Paraffin Hydrocarbons. Izvestiya Akademii Nauk SSSR, Seriya Khimicheskaya, 40-45.

[13] Vinogradova, V.G., Bondareva, N.K. and Zverev, A.N. (1976) Oxidation of Hydrocarbons in the Presence of Additives of Sulfur-Containing Compounds of Copper(I). Izvestiya Akademii Nauk SSSR, Seriya Khimicheskaya, 1947-1950.

[14] Macko, L. (1971) Investigation of Oxidation Kinetics of Transformer Oils by Polarography. Ropa a Uhlie, 13, 659664. 
[15] Matsumura, S. and Miyazaki, T. (1974) Experiments on Copper Corrosion in Insulating Oil. Sekiyu Gakkaishi, 17, 560-563. http://dx.doi.org/10.1627/jpi1958.17.560

[16] Copper Corrosion Inhibitors in Lubricationg Oils. DE 2413145 to Mobil Oil Corp, 1974.

[17] Copper Corrosion-Inhibiting Insulating Oil. JP 49114099 to Kanden Hankyu Shoji Co., 1973.

[18] Water Containing Functional Fluids Comprising an Oil Soluble Dimercaptothiadiazole Compound or Derivative. EP 1191087A1 to Chevron Oronite Company LLC, 2001.

[19] Walker, R. (1973) Benzotriazole as a Corrosion Inhibitor for Immersed Copper. Corrosion, 29, 290-296. http://dx.doi.org/10.5006/0010-9312-29.7.290

[20] Fox, P.G., Lewis, G. and Boden, B.J. (1979) Some Chemical Aspects of the Corrosion Inhibition of Copper Benzotriazole. Corrosion Science, 19, 457-467. http://dx.doi.org/10.1016/S0010-938X(79)80052-9

[21] Sastri, V.S. (1998) Corrosion Inhibitors: Principles and Applications. Wiley, Chichester.

[22] Sevastyanova, O., Li, J. and Gellerstedt, G. (2006) On the Reaction Mechanism of the Thermal Yellowing of Bleached Chemical Pulps. Nordic Pulp \& Paper Research Journal, 21, 188-192. http://dx.doi.org/10.3183/NPPRJ-2006-21-02-p188-192

[23] Morais, R.M. and Engelstein, E. (1990) Thermal Aging of Oil-Paper Insulation. 10th International Conference on Conduction and Breakdown in Dielectric Liquids, Grenoble, 10-14 September 1990, 495-499.

[24] Nanba, S. and Miyamoto, T. (1992) Adsorption Phenomenon of Furfural in Insulation Paper (Fundamental Test for Life Diagnosis of Transformer). Transactions of the Institute of Electrical Engineers of Japan, 112A, 139-144.

[25] Pahlavanpour, B., Eklund, M. and Martins, M.A. (2003) Insulating Paper Ageing and Furfural Formation. Proceedings of Electrical Insulation Conference and Electrical Manufacturing \& Coil Winding Technology Conference, Indianapolis, 23-25 September 2003, 283-288. http://dx.doi.org/10.1109/EICEMC.2003.1247898

[26] Beyer, M., Lind, A., Koch, H. and Fischer, K. (1999) Heat-Induced Yellowing of TCF-Bleached Sulphite Pulps. Journal of Pulp and Paper Science, 25, 47-51.

[27] Granstrom, A., Gellerstedt, G. and Eriksson, T. (2002) On the Chemical Processes Occurring during Thermal Yellowing of a TCF-Bleached Birch Kraft Pulp. Nordic Pulp \& Paper Research Journal, 17, 427-433. http://dx.doi.org/10.3183/NPPRJ-2002-17-04-p427-433

[28] de Pablo, A. and Pahlavanpour, B. (1997) Furanic Compounds Analysis: A Tool for Predictive Maintenance of OilFilled Electrical Equipment. Electra, 175, 8-32.

[29] Dong, M., Zhou, M.G., Qu, Y.M. and Yan, Z. (2005) Synthetic Furfural Analysis for Paper Insulation Ageing Diagnosis of Transformer. Proceedings of 2005 International Symposium on Electrical Insulating Materials, Vol. 2, Piscataway, 5-9 June 2005, 439-442. http://dx.doi.org/10.1109/iseim.2005.193583

[30] Arney, J.S. and Jacobs, A.J. (1979) Accelerated Ageing of Paper. The Relative Importance of Atmospheric Oxidation. Tappi, 62, 89-91.

[31] Piskorz, J., Radlein, D. and Scott, D.S. (1986) On the Mechanism of the Rapid Pyrolysis of Cellulose. Journal of Analytical and Applied Pyrolysis, 9, 121-137. http://dx.doi.org/10.1016/0165-2370(86)85003-3

[32] Li, J., Henriksson, G. and Gellerstedt, G. (2005) Carbohydrate Reactions during High-Temperature Steam Treatment of Aspen Wood. Applied Biochemistry and Biotechnology, 125, 175-188. http://dx.doi.org/10.1385/ABAB:125:3:175

[33] Nonier, M.F., Vivas, N., Vivas de Gaulejac, N., Absalon, C., Soulie, P. and Fouquet, E. (2006) Pyrolysis-Gas Chromatography/Mass Spectrometry of Quercus sp. Wood: Application to Structural Elucidation of Macromolecules and Aromatic Profiles of Different Species. Journal of Analytical and Applied Pyrolysis, 75, 181-193. http://dx.doi.org/10.1016/j.jaap.2005.05.006

[34] Haynes, E.M. (1978) Method and Apparatus for Detecting Water in Oil. US Patent No. 4,129,501.

[35] Campbell, et al. (2002) Insulating Oil Leak Containment. US Patent No. 6,476,723.

[36] Bukhtiyarov, et al. (2002) Method for Dehydrating Crude Oil and Petroleum Products and Device for Realizing the Same. US Patent No. 6,395,184.

[37] Butler, et al. (1997) Transformer Leak Alarm. US Patent No. 5,691,706.

[38] Garrett, L.W. (1985) Process for Treating Contaminated Transformer Oil. US Patent No. 4,498,992.

[39] Ingold, K.U. (1959) Kinetics of Oil Oxidation Inhibitors. Journal of the Institute of Petroleum, 45, $244-251$.

[40] Wiklund, P. (2007) The Response to Antioxidants in Base Oils of Different Degrees of Refining. Lubrication Science, 19, 169-182. http://dx.doi.org/10.1002/ls.38

[41] Maina, R., Scatiggio, F., Kapila, S., Tumiatti, V., Tumiatti, M. and Pompilli, M. (2006) Dibenzyl Disulfide (DBDS) as Corrosive Sulfur Contaminant in Used and Unused Mineral Insulating Oils. Report Circulated within IEC TC10 WG35. 
[42] Amaro, P.S., Holt, A.F., Facciotti, M., Pilgrim, J.A., Lewin, P.L., Brown, R.C.D., et al. (2013) Impact of Corrosive Sulphur in Transformer Insulation Paper. 2013 IEEE Electrical Insulation Conference (EIC), Ottawa, 2-5 June 2013, 459-463.

[43] Li, J., He, Z., Bao, L. and Yang, L. (2011) Influences of Corrosive Sulphur on Copper Wires and Oil-Paper Insulation in Transformers. Energies, 4, 1563-1573. http://dx.doi.org/10.3390/en4101563

[44] Hao, J., Liao, R., Chen, G. and Ma, C. (2011) Influence of Copper on the By-Products of Different Oil-Paper Insulations. Journal of Physics: Conference Series, 310, Article ID: 012007. http://dx.doi.org/10.1088/1742-6596/310/1/012007

[45] Derin, H. and Kantarli, K. (2002) Optical Characterization of Thin Oxide Films on Copper by Ellipsometry. Applied Physics A: Materials Science and Processing, 75, 391-395. http://dx.doi.org/10.1007/s003390100989

[46] Castle, J.E., Whitefield, T.B. and Ali, M. (2003) The Transport of Copper through Oil-Impregnated Paper Insulation in Electrical Current Transformers and Bushings. IEEE Electrical Insulation Magazine, 19, 25-29. http://dx.doi.org/10.1109/MEI.2003.1178105

[47] Gromov, V.K., Chalykh, A.Ye., Vasenin, R.M. and Voyutskii, S.S. (1965) Ceresin Diffusion in Saturated CarbonChain Polymers. Vysokomolekulyarnye Soedineniya, 7, 2117-2121. http://dx.doi.org/10.1016/0032-3950(65)90169-3

[48] Glasstone, S., Laidler, K.J. and Eyring, H. (1941) The Theory of Rate Processes. McGraw-Hill, New York. 